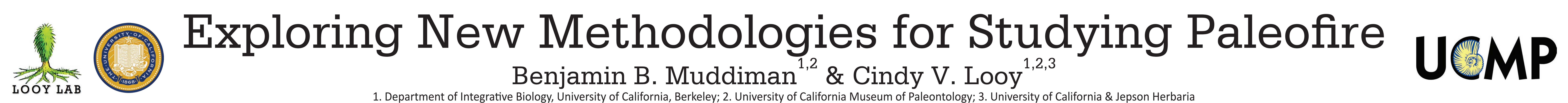

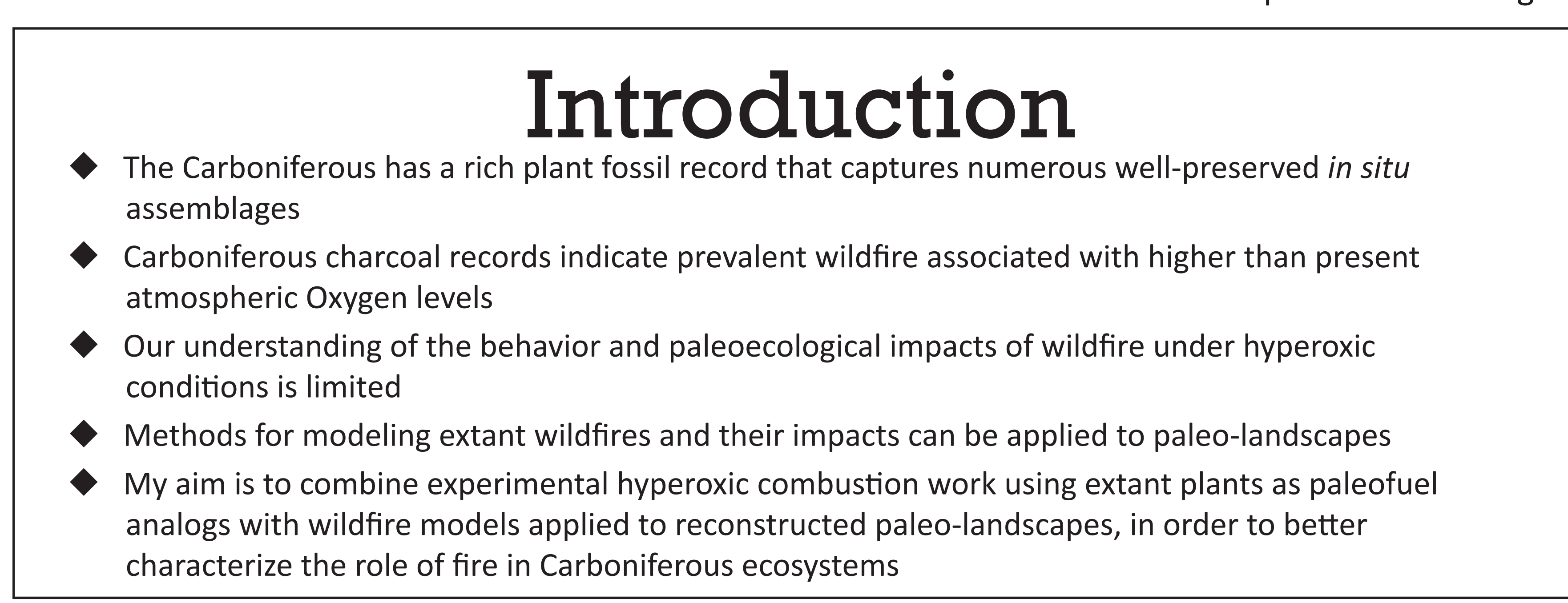

\section{Types of Wildfire}

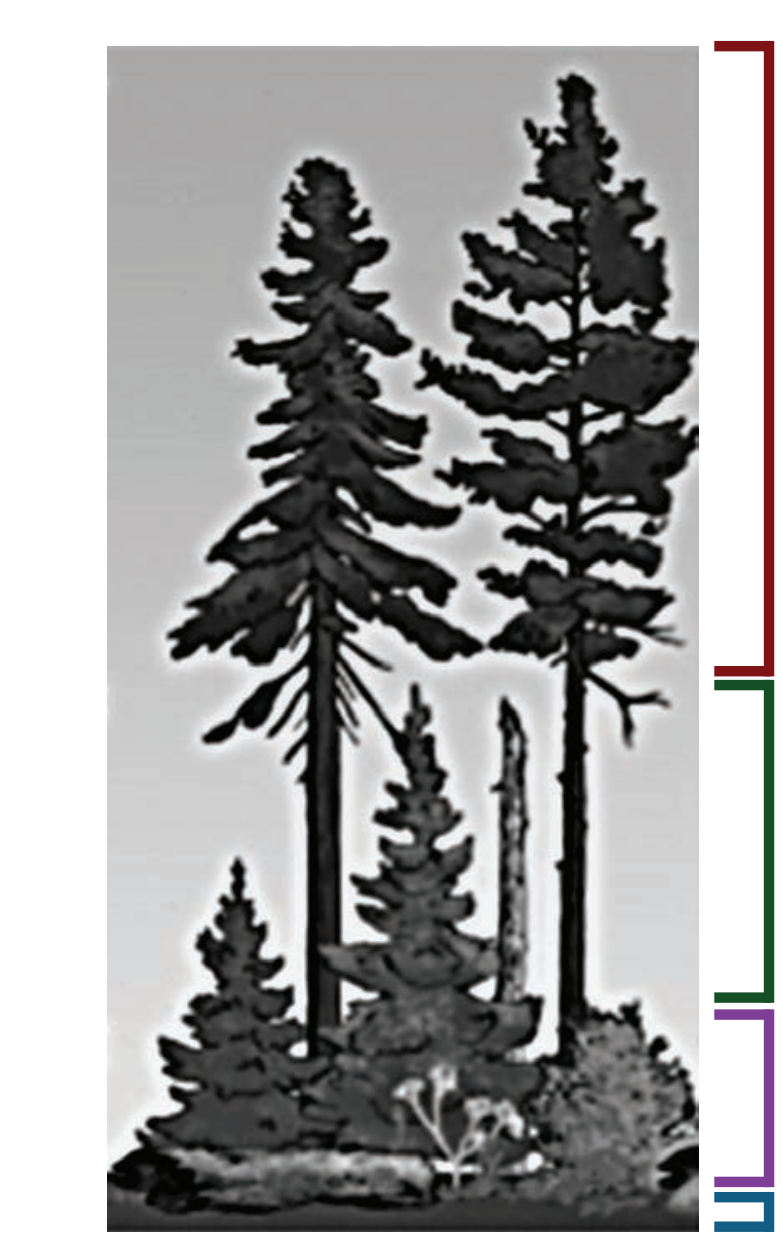

ddder Fuels: intermediate height trees and shrubs, lower fire transition.

Surface Fuels: duff, litter, surface logs, shrubs, grasses. Most consumed layer ders
restoration efforts

Ground Fuels: deep duff, roots, buried logs. Sometimes
smolders instead of undergoing flaming combustion.
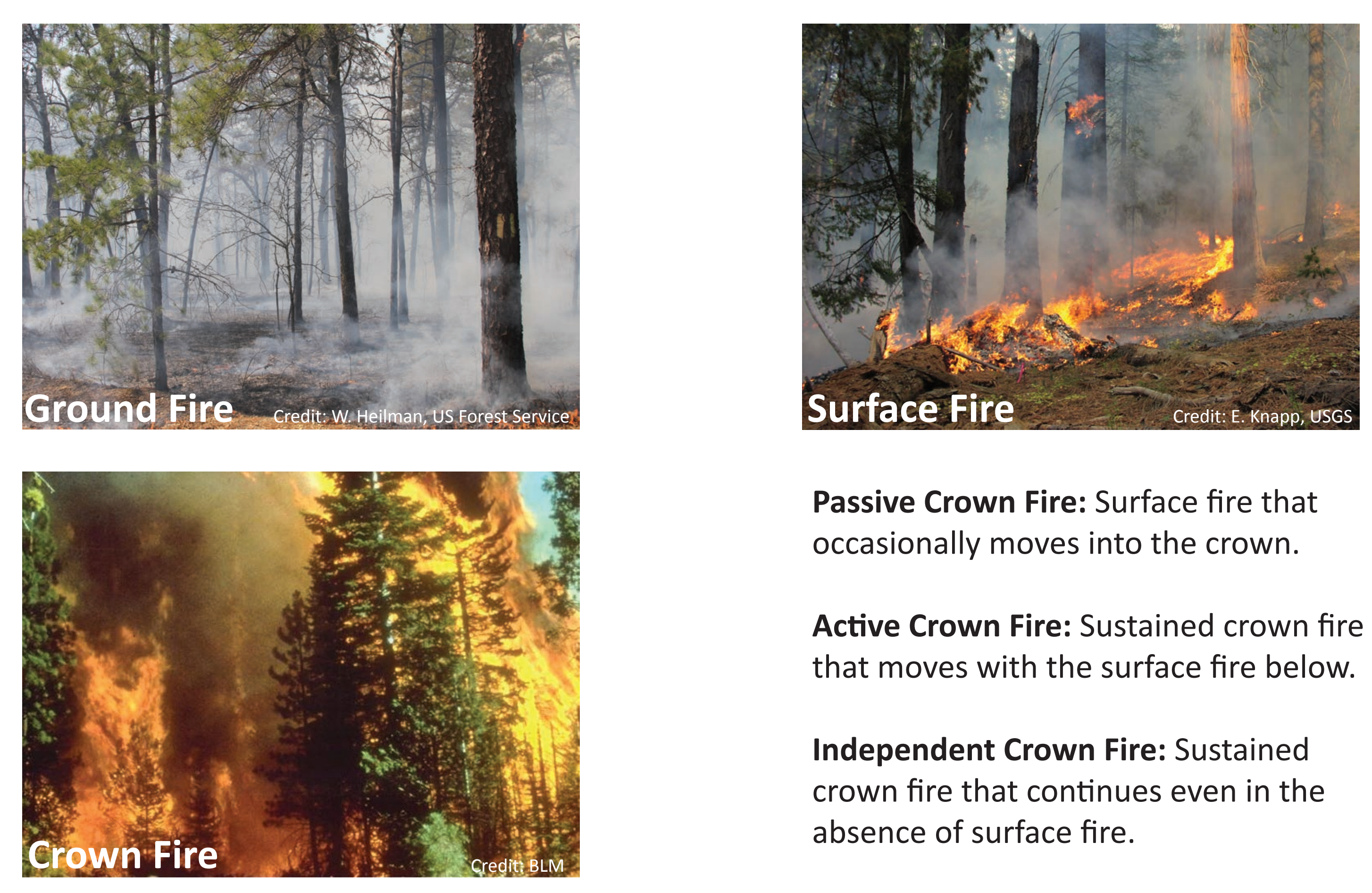

Passive Crown Fire: Surface fire that
occasionally moves into the crown.

Active Crown Fire: Sustained crown fire
that moves with the surface fire below.

Independent Crown Fire: Sustained
crown fire that continues even in the
absence of surface fire.

\section{Describing Wildfire}
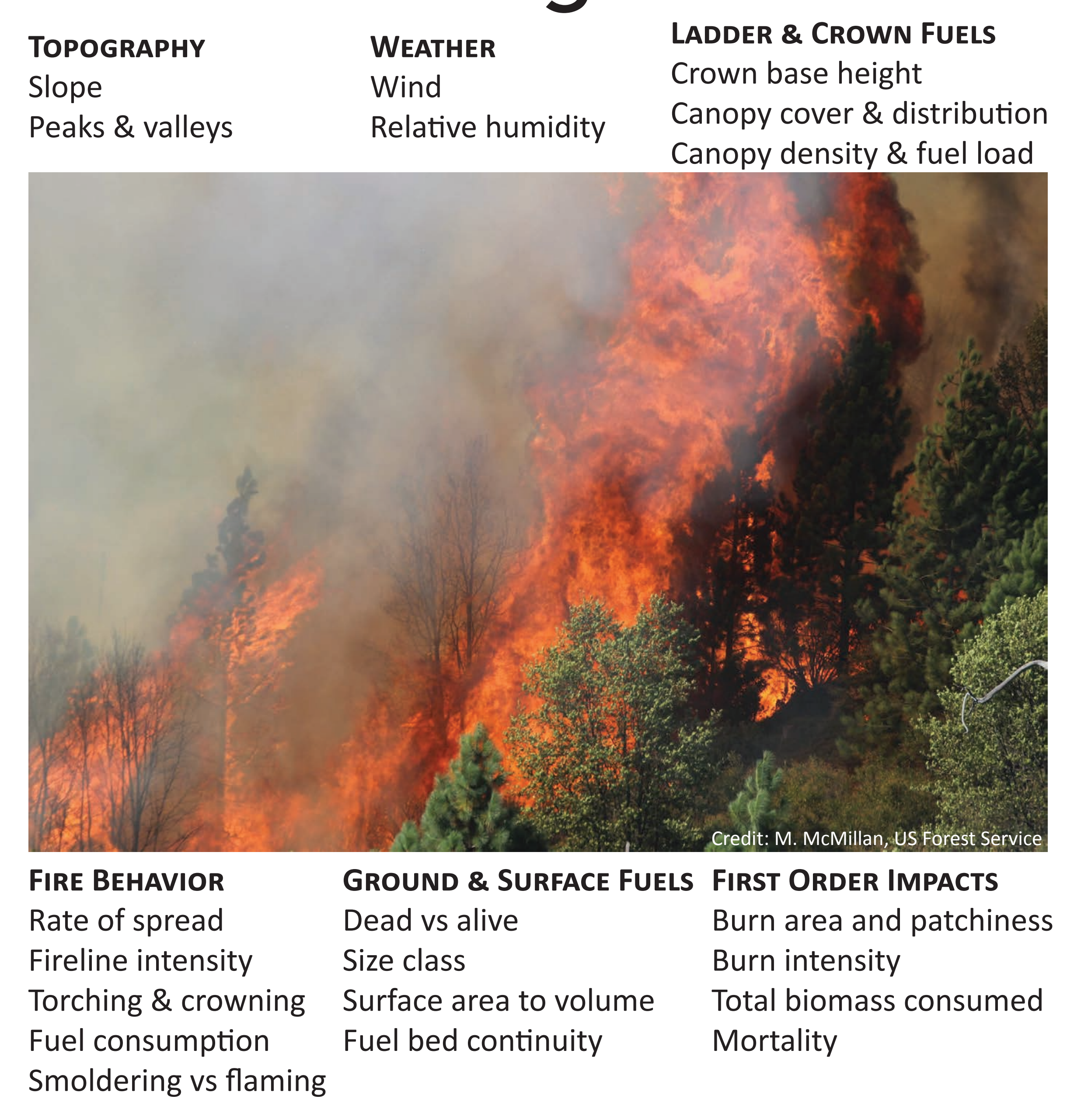

\section{Modeling Wildfire}

PSEUDOEMPIRICAL MODELS Use a combination of simplified physical descriptions of fire behavior and empirical measurements.
Most commonly used programs are based on the Frandsen-Rothermel equations, which model fire
spread as a series of ignitions.

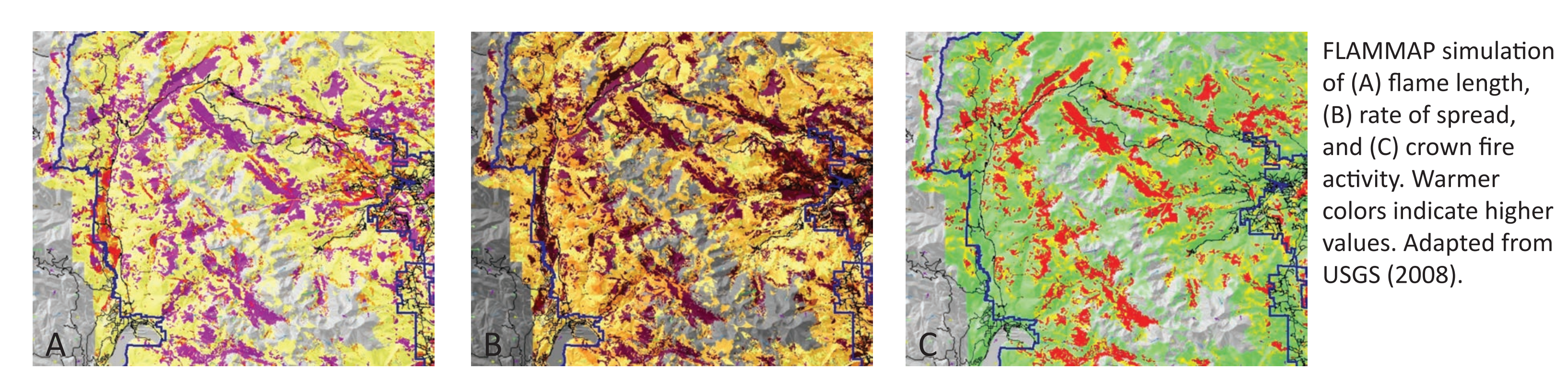

Benefits: Computationally fast, widely implemented, effective within well-defined scope. Drawbacks: Inherently limited outside of original experimental scope; require empirical input; lim ited ability for modeling crown fire; unable to model smoldering combustion or spotting behavio Use first principles of physics and thermodynamics along with explicit models of the chemistry of
combustion to describe fire behavior. These models still require empirical work for validation.

Cenits: Can ber

Drawbacks: Validation is still a critical challenge; computationally slow; accurate description of all the physical processes involved and their contributions at various spatiotemporal scales is ongoin
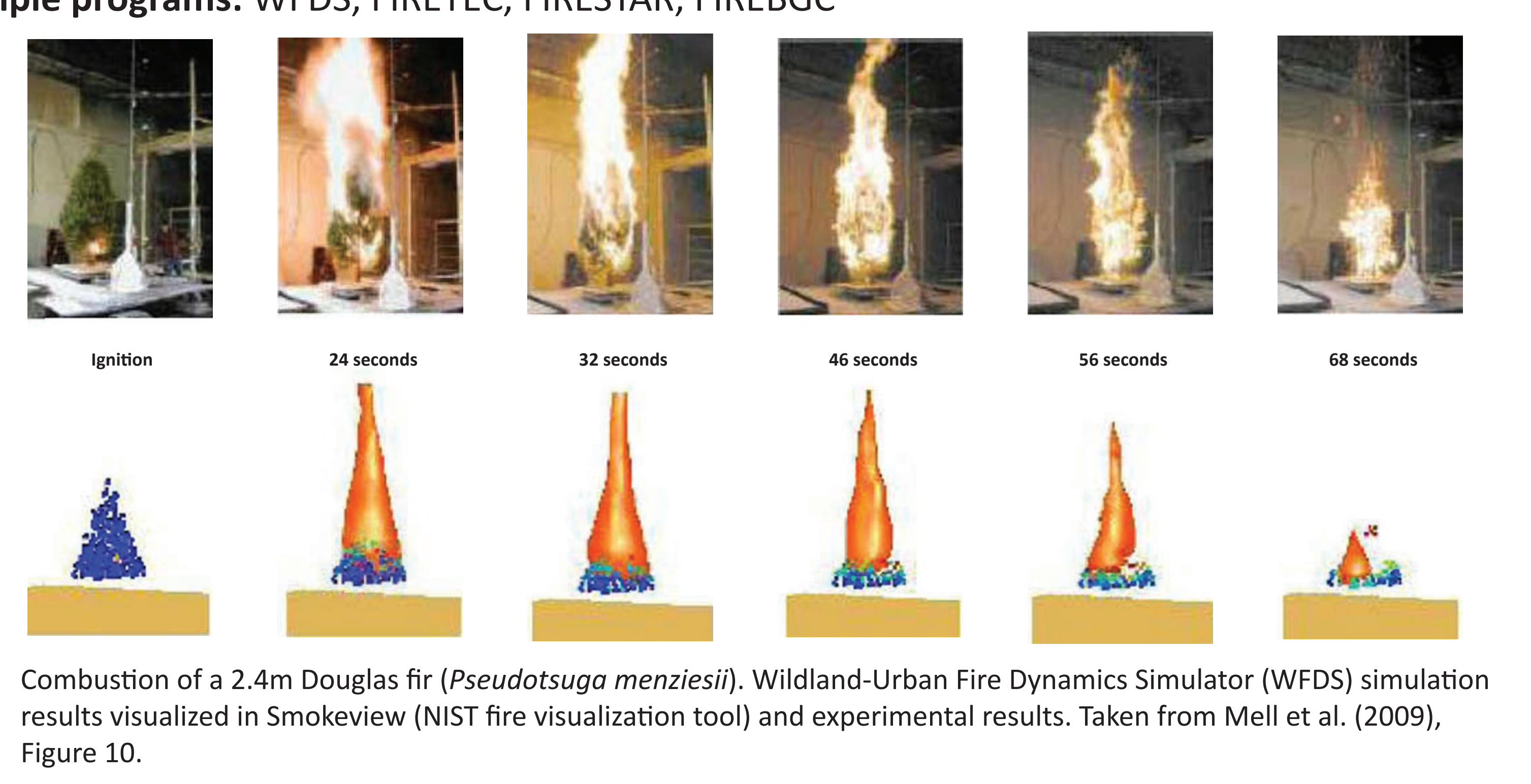

Proposed Research

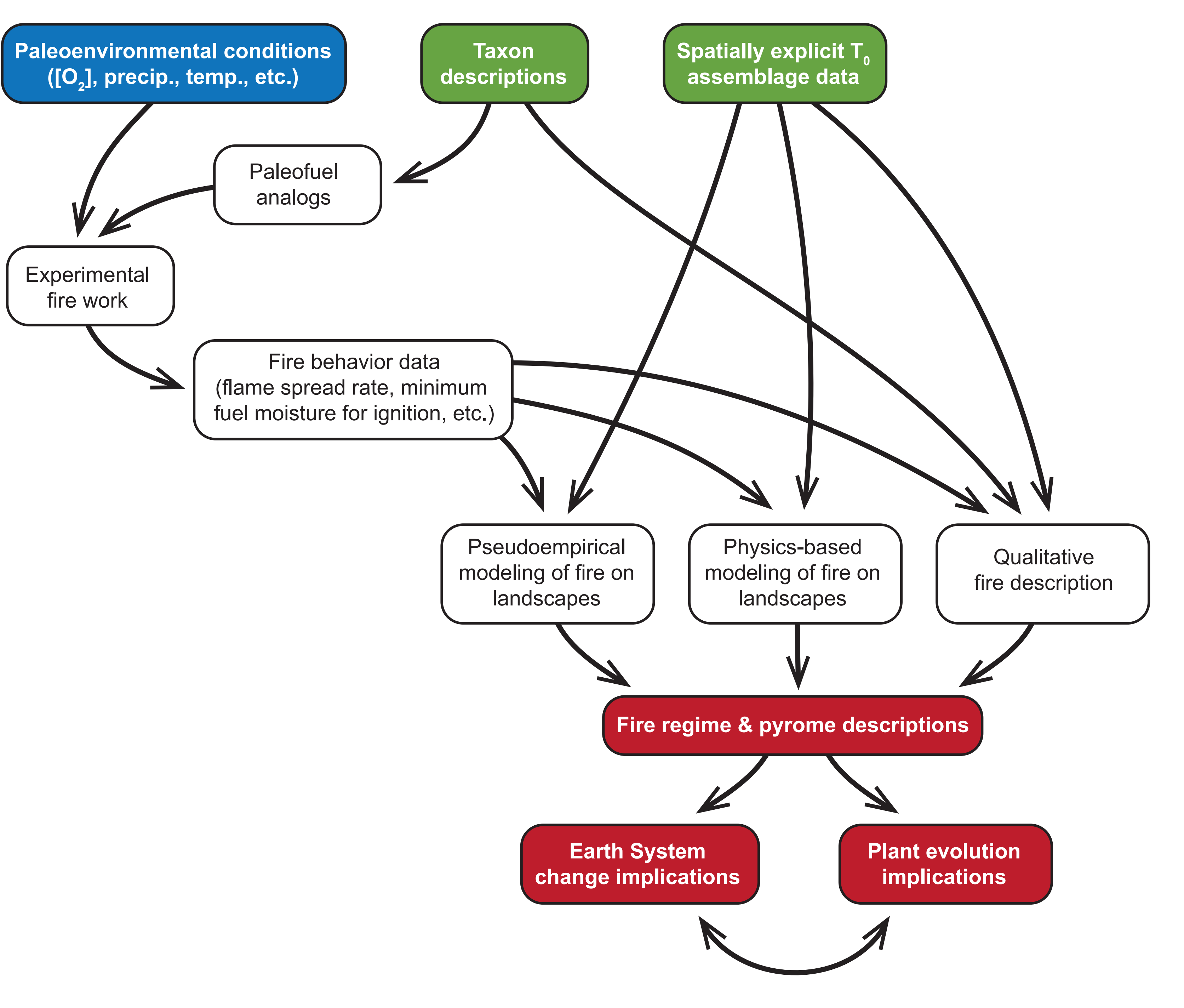

Fire in the Carboniferous ATMOSPHERIC OXYGEN LeVELS THROUGH TIME

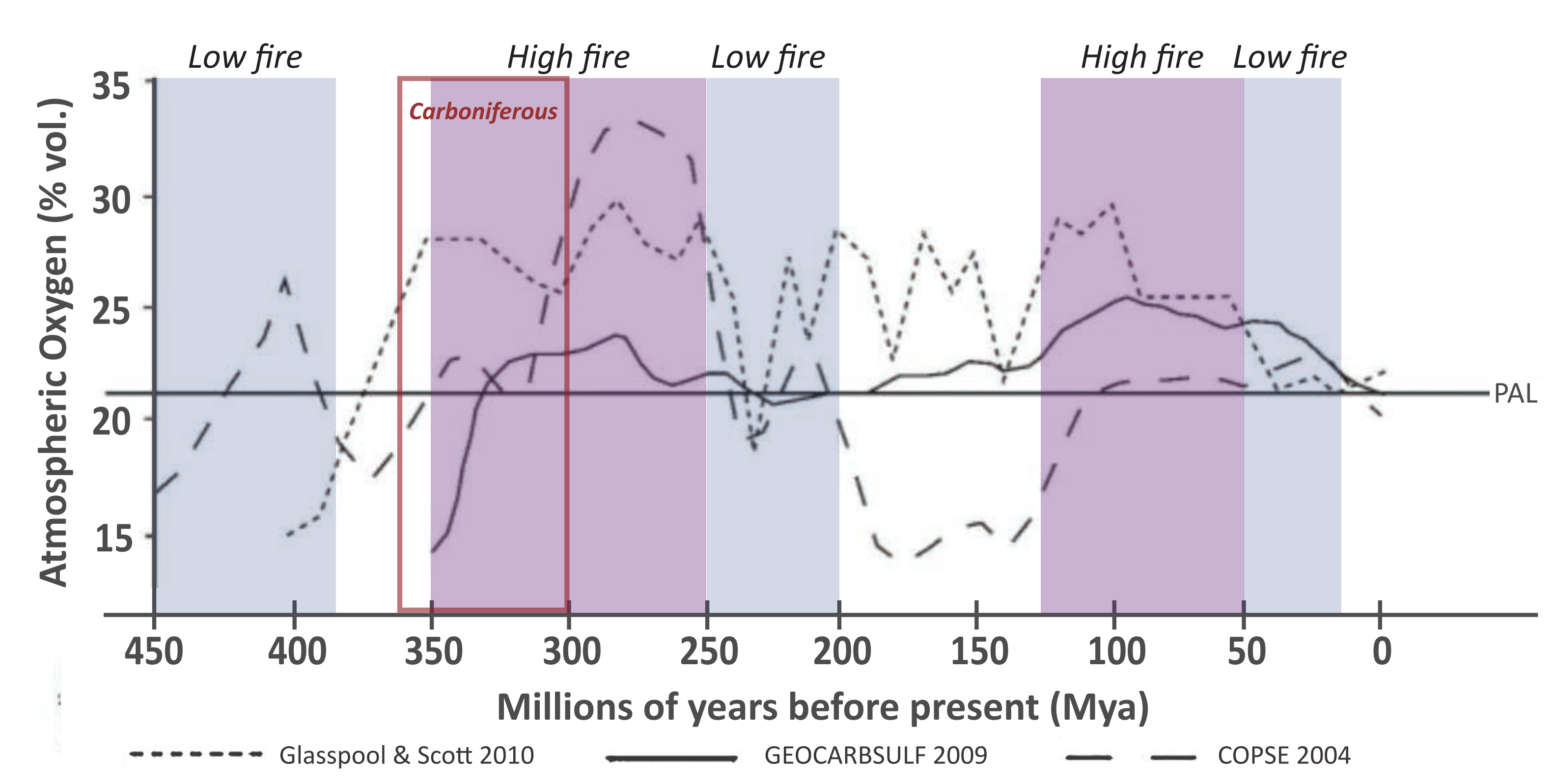

Reconstructions of paleoatmospheric Oxygen levels from Glasspool \& Scott's (2010) Oxygen proxy method, Beve high fire activity are indicated in purple; ; those with low fire activity are highlighted in inght blue. PAL
hefers

Reconstruction of a Carboniferous Peat SWAmp

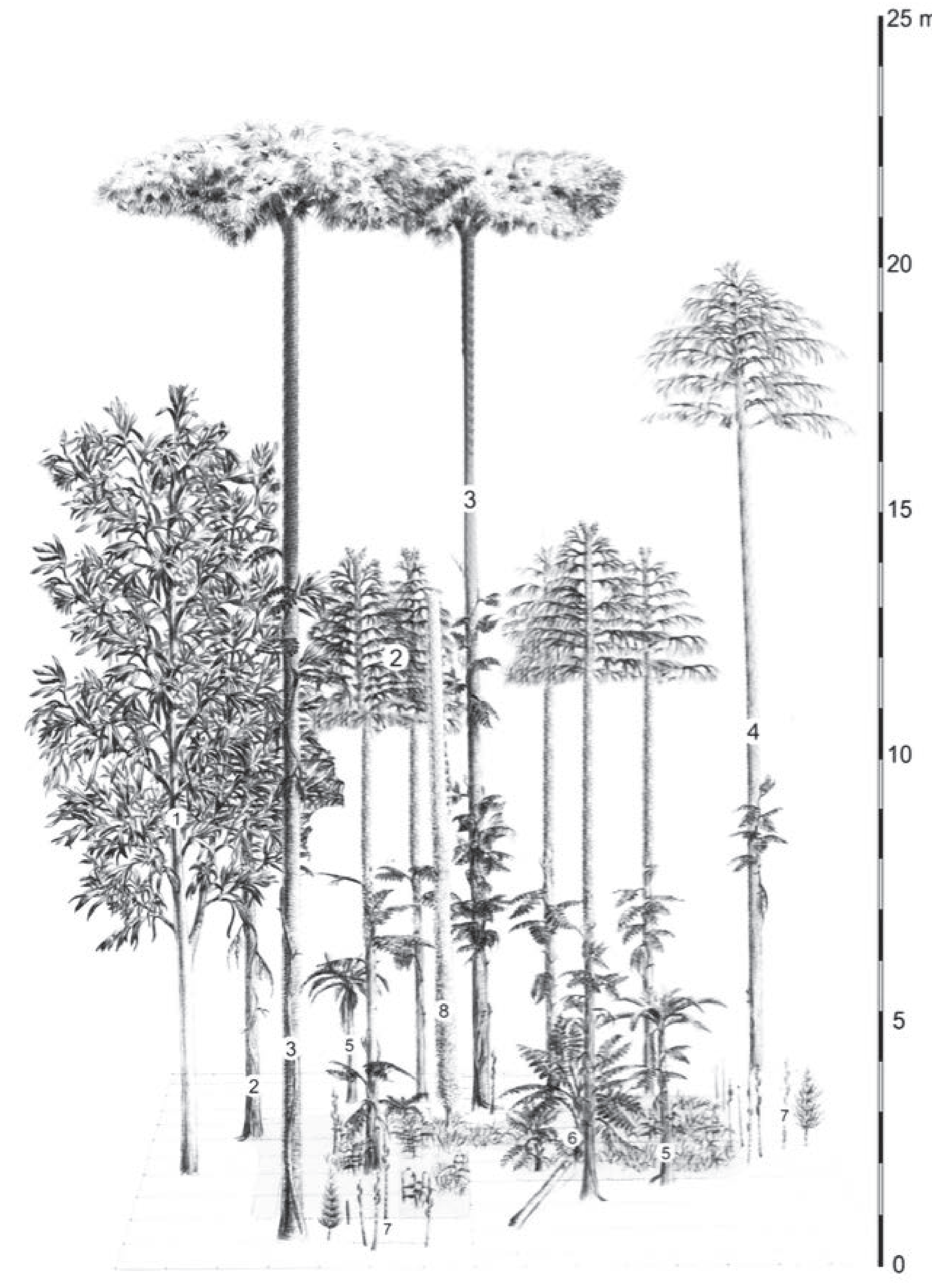

Coal. Taken from Oplustili et at I. (2009), Figure 23. This s spatially explicitit in sittu assemblage highhights

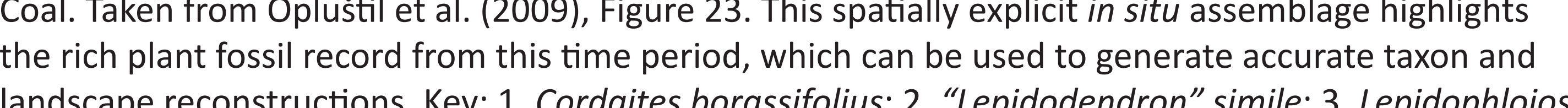

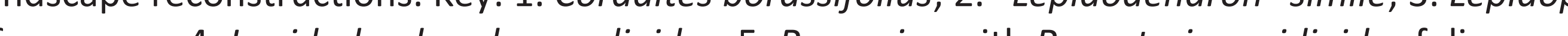

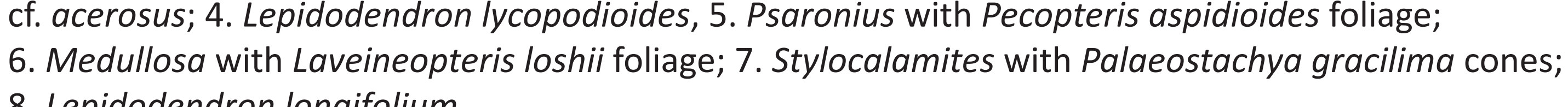

Acknowledgments $\mathrm{g}^{2}$, and Scott Stephens ${ }^{3}$ for their support and adv $\mathrm{C}^{2}$

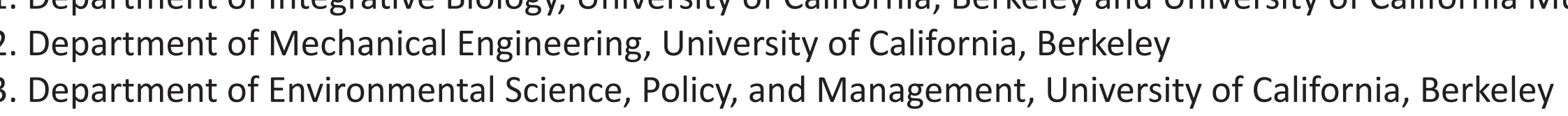

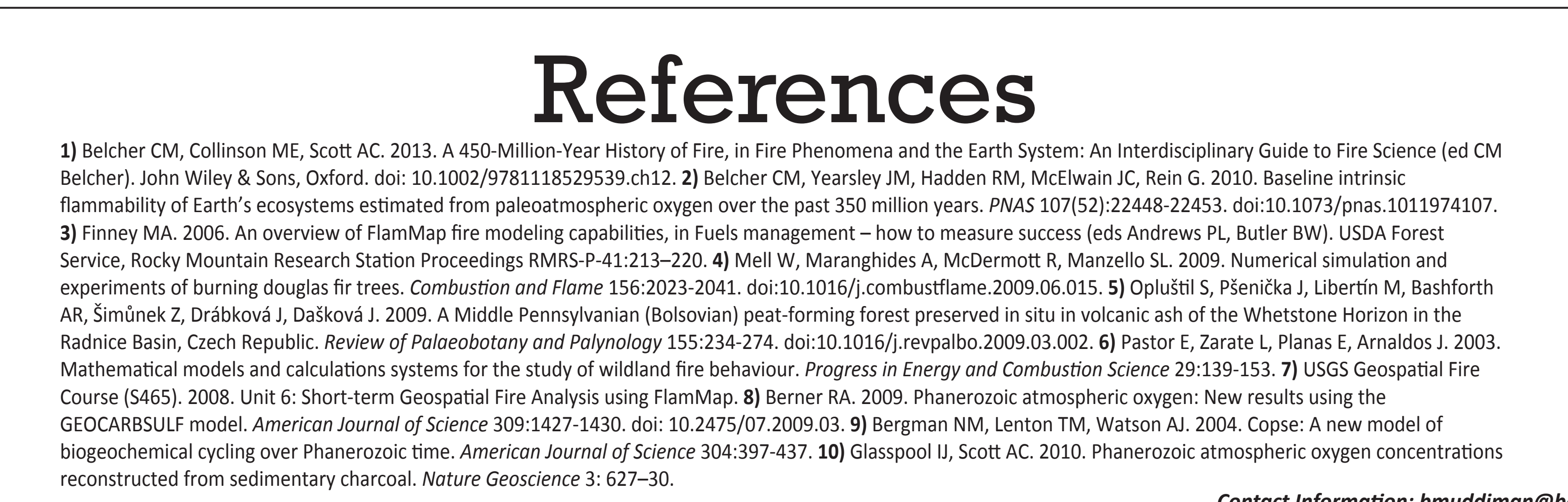

